\title{
EL LOGOS MEDIADOR EN FILÓN DE ALEJANDRÍA
}

THE MEDIATOR LOGOS IN PHILO OF ALEXANDRIA

\author{
MATÍAS DÍAZ-LISBOA* \\ Lcdo. en Filosofía \\ Pontificia Universidad Católica de Chile
}

Artículo recibido el 27 de julio de 202I; aceptado el 25 de diciembre de 2021.

"matiadiaz@ug.uchile.cl

https://orcid.org/0000-0002-5602-470I

Cómo citar este artículo:

DÍAZ LISBOA, M. "El Logos mediador en Filón de Alejandría" en Palabra y Razón. Revista de Filosofía, Teología y Ciencias de la Religión. No 20 DICIEMBRE 202I, pp.33-53 https://doi.org/I0.29035/ pyr.20.33 


\title{
RESUMEN
}

El objetivo de este trabajo es analizar y sistematizar uno de los temas más importantes en torno al pensamiento de Filón de Alejandría, su teoría del Logos. Primariamente, en la introducción se mostrará cómo ha sido tratada la teoría del Logos en Filón, teoría que solo ha puesto la atención en algunas características del Logos, para posteriormente (en los siguientes capítulos) reconstruir una doctrina que está en todas las formas en que Filón trabaja el concepto de Logos, la noción del Logos como mediador, noción supuesta por todos los estudiosos, pero no explicitada. Teniendo como base este concepto de Logos mediador, se examinará en la estructura de la investigación el rol clásico que ha jugado la concepción del Logos como un instrumento, para evidenciar las dificultades de esta comprensión, y, con ello, poder acceder a la radicalidad del Logos filoniano. Propuesta que se abordará mediante el examen de algunos ejes centrales que develen los rasgos específicos de la teoría filoniana del Logos, como son (I) el problema de la mediación en el esquema de la creación, (2) el Logos en sí mismo, (3) su independencia y (4) necesidad en el pensamiento de Filón.

Palabras claves: Logos / mediador / en sí mismo / Filón / instrumento

\begin{abstract}
The objective of this work is to analyze and systematize one of the most important topics around the thought of Philo of Alexandria, his theory of the Logos. Primarily, the introduction will show how the theory of the Logos in Philo has been treated, a theory that has only paid attention to just some aspects of the Logos, for later (in the following chapters) to reconstruct a doctrine that is in all the forms in which Philo works on the concept of Logos, the notion of the Logos as a mediator, a notion assumed by all scholars, but not explained. Based on this concept of mediator Logos, the classical role that the conception of the Logos as an instrument has had will be examined in the structure of the investigation, to show the difficulties of this understanding, and, with it, to be able to access the radicality of the Philonian logos. The proposal that will be approached by examining some central features that reveal the specific characteristics of the Philonian theory of Logos, such as (I) the problem of mediation in the scheme of creation, (2) the Logos itself, (3) its independence and (4) its necessity in Philo's thought.
\end{abstract}

Keywords: Logos / mediator / in itself / Philo / instrument 


\section{Introducción}

Al pensamiento de Filón de Alejandría tanto la patrística, como toda la Edad Media, le debe mucho, pues gracias a él se inicia un tipo de especulación filosófica motivada por un conjunto de creencias religiosas; reflexión que será acompañada por un método de interpretación que tejerá el pensamiento semita y helénico. Una gran prueba de lo anterior es el platonismo que logró conjugar, para la creación de conceptos claves de la tradición platónica y cristiana posterior, como el conocido kó von ó $^{1}$ o mundo inteligible, que alberga las ideas platónicas ${ }^{2}$ y no es otra cosa en Filón que la Palabra de Dios, el Logos divino. Acerca de este

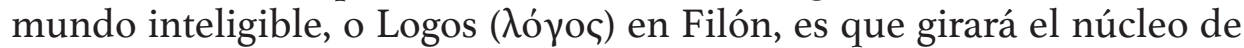
esta investigación.

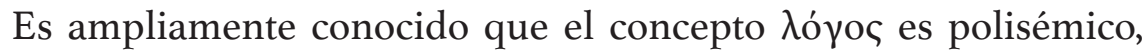
y, por esta característica, lo podemos encontrar de manera variada en el Corpus Philonicum. Acerca del abanico de posibles significaciones que puede adquirir esta palabra cabe destacar tres ámbitos en los que se desarrolla el Logos, que son: (I) intra-divino, (2) cosmológico y (3) antropológico.

Cada uno de estos planos son en gran medida extensos y de ellos se ha escrito mucho, generalmente colocando el acento en ciertas características que comporta el Logos en cada uno de ellos. En el intra-divino, el Logos es identificado con la causa ( $\alpha i \tau i \alpha)$ del todo ${ }^{3}$-de la creación-, que siendo la causa permite salvaguardar los atributos principales del Existente ( $\tau$ ò ő $v$ ) como la de ser, su simplicidad y unidad ${ }^{4}$. En el plano cosmológico el Logos se manifiesta como el principio ( $\alpha \rho \chi \eta \dot{)}$

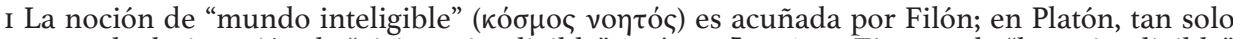

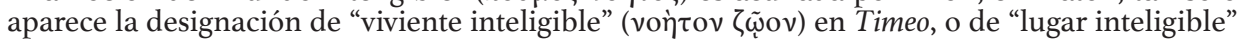

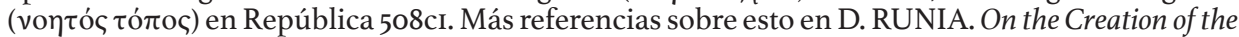
Cosmos According to Moses. Society of Biblical Literature: Atlanta, 200I, p. I36. Todo el platonismo

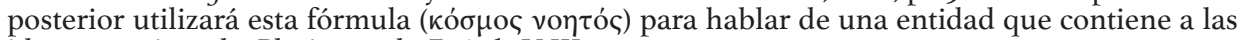
ideas, por ejemplo, Plotino en la Enéada V III, I6, IO-I5.

2 Ideas que en la inteligencia divina serán posteriormente interpretadas como pensamientos de Dios, esto en San Agustín, De Ideis 46, 2.

3 Opif. 2I. Además de aparecer el Logos en este plano como causa de la creación, también es caracterizado por Filón y ha sido estudiado por la tradición como el modelo bello ( $\mu$ í $\mu \eta \mu \alpha \kappa \alpha \lambda$ òv)

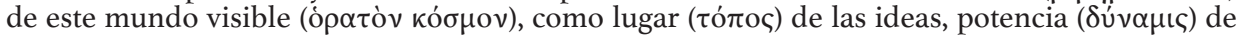
Dios y como el que ordena $(\delta เ \alpha \kappa o \sigma \mu \tilde{\omega} v)$ las ideas, como se puede ver en Opif. I6; 20. Se sigue en el presente trabajo el modo clásico de citar a Filón, según las abreviaturas correspondientes en los Studia Philonica, para el texto griego se ha seguido la edición de Cohn, Wendland y Reiter, y, para su traducción nos hemos guiado principalmente por la traducción española de José Martín y la italiana de Roberto Radice, las referencias de estos más abajo.

4 Gracias a una no relación directa del Existente y la multiplicidad. El ser en Mut. II. Simplicidad Leg. II, 2. Y, unidad Opif. I7I.
} 
más antiguo $(\pi \rho \varepsilon \sigma \beta u ́ \tau \alpha \tau o \varsigma)^{5}$, divisor $(\tau o \mu \varepsilon ́ v \varsigma)^{6}$ y vínculo $(\delta \varepsilon \sigma \mu o ́ \varsigma)$ del universo ${ }^{7}$. Y, por último, en el plano antropológico es representado el Logos principalmente como la parte rectora del alma ${ }^{8}$. El Logos filoniano es en gran medida amplio por el gran espectro que cubre en la hermenéutica filoniana, pero dentro de esta multiplicidad, resalta para cualquier lector un rasgo distintivo por sobre cualquier otro, la noción del Logos como mediador.

La noción de mediador como característica esencial del Logos ha sido destacada por la mayoría de los estudiosos del pensamiento del alejandrino (como veremos). Pero, a pesar de esta unanimidad, en su gran mayoría no se ha profundizado en este concepto, solo se ha dado por supuesto para el análisis de cualquier otra manifestación del Logos. Por ejemplo, José María Triviño en la introducción a su traducción de las obras completas de Filón nos dice que el Logos es un "ser intermediario"9. Del mismo modo, José Pablo Martín nos dice: "La dimensión del lenguaje es de mediaciones: el logos divino adquiere funciones mediadoras múltiples" Io. También, Maren Niehoff en su reciente obra "Philo of Alexandria. An Intellectual Biography" titula el capítulo dedicado al Logos: "The Logos as Intermediary" y nos dice que "There is a broad consensus that the Logos functions as a mediator between God and the material real and, moreover, that some mixing of ideas is involved" ". Otro es Scott Mackie quien investigando sobre la visio dei en Filón de Alejandría, no puede evitar mencionar el lugar que ocupa el Logos como un intermediario entre Dios y su creación ${ }^{12}$. Y, así se podrían dar muchos más ejemplos del acuerdo en la importancia de tan crucial característica "mediadora" del Logos ${ }^{13}$.

5 En Her. II5-II6., Det. II8., Post. I27.

6 En Her. 130-I43.

7 En Fug. II2. Además de esas manifestaciones, se pueden sumar algunos atributos del Logos en relación con la cosmología que nos plantea Filón, por ejemplo, el Logos entendido como ley de la naturaleza (vó Deus. I8o., Mut. II4-II5.

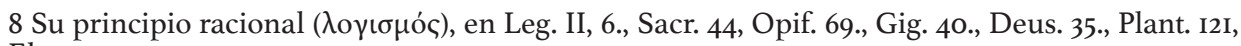
Ebr. 34 .

9 J. TRIVIÑO. Obras Completas de Filón de Alejandría. Acervo Cultural: Buenos Aires, 1976, p.22.

Io J. MARTÍN (ed.). Filón de Alejandría. Obras Completas I. Trotta: Madrid, 2009, p.6o.

II M. NIEHOFF. Philo of Alexandria. An Intellectual Biography. Yale University Press: New Haven, 20I8, p.217.

I2 S. MACKIE. "Seeing God in Philo of Alexandria: Means, Methods, and Mysticism" en The Studia Philonica Annual 2I (2009), pp. I47-I79, p.29. Disponible en: https://doi.org/I0.II63/1570063I2X617344 I3 Para comprender el carácter universal que ha adquirido entre los eruditos del pensamiento de Filón esta caracterización del Logos como mediador o intermediario, se puede revisar la referencia a esta cualidad primordial del Logos en la clásica traducción de Colson y Whitaker en F. COLSON - G. WHITAKER (trad.). "Introducción" en PHILO. IN TEN VOLUMES (AND TWO SUPPLEMENTARY VOLUMES). I. Harvard University Press: Cambridge, I98I, p. XIX. O, también 
Esta coincidencia en el rol mediador contrasta con la ausencia de un examen sistemático entre los comentaristas, lo que podría justificarse en el hecho que el propio Filón no se dedica sino puntualmente a examinar esta cualidad de manera detallada. Así, en Filón mismo la mediación es una cualidad aludida pero nunca explicada en mayor profundidad, lo que no significa, sin embargo, que estas alusiones sean irrelevantes o superficiales en contenido ${ }^{\mathrm{I}}$.

\section{El Logos mediador como instrumento}

En gran medida, la idea que se ha tenido en la contemporaneidad acerca del Logos como intermediario o mediador, ha sido reducida a su función de "instrumento" (ö $\rho \gamma \alpha v o v)^{15}$.

Para poder realizar un análisis completo de la idea de instrumento en Filón, es necesario primero acudir al texto primordial en el que se presenta al Logos como instrumento, para poder rastrear en qué sentido Filón está entendiendo esta noción ${ }^{16}$. Filón nos dice en De Cherubim que,

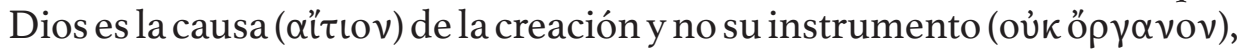
pues lo que llega a ser "por medio" del instrumento ( $\delta$ ' ó $\rho$ yó vou) depende de una causa mayor, la causa de todo, que es Dios. Luego de esto, Filón evoca las causas que se necesitan para la generación; estas son "aquello

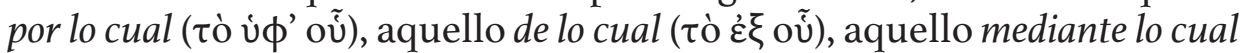

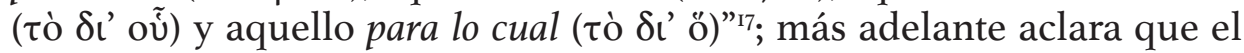
mediante lo cual está haciendo referencia al Logos, en Cher. I27.

en la traducción francesa en R. ARNALDEZ (trad.). "Introduction generale" en De Opificio Mundi. Éditions du Cerf: Paris, I96I, p. I03.

I4 Entre los comentaristas destaca la investigación de Wolfson, quien sí indica lugares de la obra de Filón en dónde encontrar esta teoría y acentúa su importancia, ver H. WOLFSON. Philo Foundations of Religious Philosophy in Judaism, Christianity, and Islam I. Harvard University Press: Massachusetts, 1962, p. 338.

I5 Esta idea de "instrumento", como es sabido, proviene del pensamiento de Aristóteles, en Metafísica 5, IOI3b2.

I6 Identificar algo como "instrumento" no basta para entenderlo en tan solo un sentido, pues como bellamente nos recordará siglos después el Doctor Angélico en su Summa Theologica: "El instrumento tiene una doble función: la primera es instrumental, según la cual actúa no por la propia virtud, sino por la virtud recibida del agente principal. La segunda es propia, y le compete por su propia forma: cortar, por ejemplo, es competencia del hacha en virtud de su propio filo" (S. T., III, 62, I, ad 2). El instrumento actúa primero por quien utiliza el instrumento y por la virtud que quien lo utiliza le imprime, pero, también actúa por su propia virtud como instrumento según su forma o función propia.

I7 En Cher. I25. "Aquello por lo cual" es la causa original de todo, la causa primera, que Filón identifica en su poder creativo con Dios, el Existente. "Aquello de lo cual" es aquello de lo que están hechas las cosas generadas, la materia. "Aquello para lo cual" es la finalidad de la cosa, es decir, aquello para lo cual está hecha la cosa, los fines propios de cada ser generado. Y, por último,

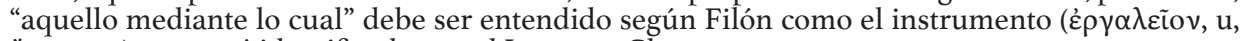
öpyavov), que será identificado con el Logos en Cher. I27. 
Este pasaje deja clara la identificación que hace Filón entre el Logos y el instrumento, y explica cómo es que el instrumento cumple la función de mediador, pues es aquello "mediante el cual" ( $\delta \iota$ ' oũ) fue hecha la creación, el instrumento que Dios utilizó para la creación, el mediador entre el Creador y la creatura. Aunque, antes de explicar el porqué de esta identificación (entre el Logos instrumento=Logos mediador), parece necesario ponerla en relación con sus fuentes clásicas; pues efectivamente sus concepciones tanto del instrumento como de la mediación son recursos que Filón toma prestados de Platón y Aristóteles. Comenzaremos con la noción de causa instrumental platónica y luego la noción de causa que media en Aristóteles.

Sobre la idea de "causa instrumental", la traductora de la versión española del De Cherubim, Paola Druille, remite a una idea particular de "causa" que aparece en Timeo 28a-c. En efecto, según Druille ya Platón distingue entre una causa instrumental y la causa de esta causa: "el ateniense utiliza la primera expresión para aludir a la causa ( $\alpha$ İ $\tau\llcorner\mathrm{v})$ por la que (ú $\phi$ ' oũ) todo ha sido creado; mientras que reserva la segunda ( $\tau$ ò $\delta \iota^{\prime}$ oũ) para referirse a la causa instrumental"18.

Filón toma prestada esta idea de "aquello mediante lo cual" ( $\tau$ ò $\delta$ ' oũ) platónica, para precisar el rol del Logos divino que, siendo instrumento para la creación, es la realidad mediante la cual el Existente puede manifestarse ante su creación como Dios, sin perder nada de su excelencia.

Además de esta concepción platónica, encontramos la aristotélica, acerca de la idea de "instrumento", algo ampliamente conocido gracias al estudio que realizó Wolfson acerca de esto en su magna obra Philo ${ }^{19}$.

Aristóteles en el libro $\Delta$ de la Metafísica ${ }^{20}$, en su exposición sobre los sentidos en que se dice la palabra "causa", nos menciona tres maneras en las que se puede entender. La primera forma es la materia de la cosa, como el bronce lo es de la estatua, lo que Filón llama, aquello de lo cual ( $\tau$ ò $\varepsilon^{\prime} \xi$ oũ) es hecha. La segunda forma de entender la "causa" es aquella que piensa el enunciado de la esencia y sus géneros, y, por último, está la

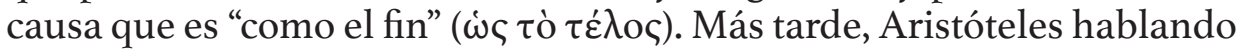

I8 J. MARTÍN (ed.). Filón de Alejandría. Obras Completas II. Trotta: Madrid, 20Io, p. 28. De manera similar en D. RUNIA. Philo Of Alexandria And The Timaeus Of Plato. Brill: Leiden, 1986, p.I72.

I9 H. WOLFSON. Philo Foundations of Religious Philosophy in Judaism, Christianity, and Islam I, 1962, pp.26I-282.

20 Todo este análisis de la fuente aristotélica sobre el concepto de "instrumento" en Filón, es interpretación del texto de Aristóteles, Metafísica 5, IOI3a24-IoI3b4. 
sobre la causa final, nos menciona que también existen algunas causas

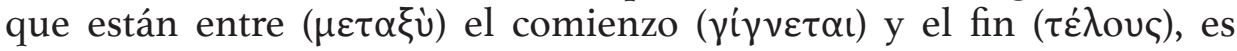
decir en el medio. Estas causas que están en el medio son instrumentos que se encuentran orientados a los fines correspondientes de cada ser creado, por ejemplo, el "adelgazamiento", pues es el medio para un fin "la salud"

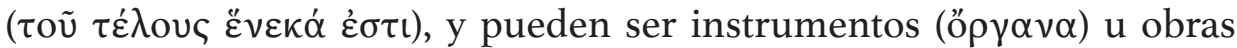
$(\varepsilon ̋ \rho \alpha)$. Filón extraerá de la teoría aristotélica de las causas, la idea que la causa instrumental ejecuta la causa final; en este caso, la "bondad" de Dios cuya meta era plasmar en la materia el modelo "bello" a través de su instrumento, de su Logos, entendido aquí como aquello que está orientado a cumplir el deseo de la bondad divina. El Logos es entonces el intermediario, la causa que según Aristóteles se encuentra "en medio" ( $\mu \varepsilon \tau \alpha \xi u ́)$, que Filón une a la causa instrumental de Platón, es decir aquella causa que permitía la creación, pero no era la "causa" original de ésta, sino que al igual que con Aristóteles, era el instrumento de su realización ${ }^{22}$.

Esta interpretación ha sido acogida por la gran mayoría de los eruditos sobre el pensamiento de Filón; incluso, la noción ha calado tan profundo que autores como Radice han llegado a decir que este atributo, el de "instrumento", es la mejor descripción del "Logos en sí" ${ }^{23}$, en su esfera separada de los demás ámbitos de la realidad.

Ahora bien, antes de pasar a la crítica de esta posición, es necesario concluir este apartado con una breve reflexión acerca de la noción de instrumento, que ya ha sido adelantada por la cita de Tomás de Aquino ${ }^{24}$, en donde se hace referencia a la doble función de un instrumento. Según el Aquinate, el instrumento puede ser entendido según la virtud del

2I Lo mismo para los instrumentos (ö $\rho \gamma \alpha v \alpha$ ) del médico, como los medicamentos que procuran el fin (que el paciente alcance la salud).

22 Estas dos fuentes que hemos mencionado, tanto la platónica, como la aristotélica en orden a esclarecer los conceptos de "mediador" e "instrumento" respectivamente, se mezclan en Filón. El instrumento aristotélico es un intermediario para la obtención de un fin, y como el instrumento al ser intermediario o causa instrumental platónica, logra ser el vínculo o medio para la creación de las cosas, y así no la causa única, pero sí una necesaria para la creación del mundo. Todas estas características calzan con la idea del Logos filoniano (instrumento y mediador) que, sin ser la causa última, que en definitiva es el Existente, se nos presenta como su primogénito

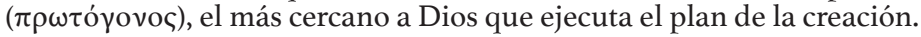

23 "La seconda dimensione del Logos, corrisponde al Logos in sé. Tale dimensione è descrita da Filone in due modi: a) in modo strettamente filosófico (e allora il Logos appare come <<strumento >> della creazione) e b) in modo metafórico, per cui esso appare in innumerevoli personificazioni.". Ver R. RADICE - G. REALE. "La concezione di Dio e la Sfera del divino: il Logos, le Idee, la Sapienza, gli angeli, il pneuma, le Potenze" en Filone Di Alessandria: Tutti I Trattati Del Commentario Allegorico Alla Biblia. Bompiani: Milano, 2005, pp. pp. 88-III, p. 90.

24 S. T., III, 62, I, ad 2. Anteriormente en la nota $\mathrm{n}^{\circ} \mathrm{I} 7$. 
agente que lo utiliza, o, según su propia virtud; esta diferenciación es totalmente pertinente al tema que estamos tratando, pues las dos formas en que entendemos el instrumento son válidas y obedecen a lo que es un instrumento, algo que es usado por otro y algo que es usado en virtud de su propia forma. En analogía con esta diferenciación sobre cómo entendemos el instrumento, es que podemos entender la dificultad existente en los estudios filonianos para definir lo que sea "el Logos en sí", pues los análisis se han restringido tan solo a la primera definición que apunta al agente que hace uso del instrumento. Tal comprensión dirige la atención sobre un solo aspecto del Logos, olvidando interrogar la causa por la que el Logos es elegido para poder ejecutar lo que el Existente realiza mediante él. Ha sido obviada la cualidad esencial sobre la que podemos realmente hablar de "Logos en sí", su mediación.

\section{El problema de la mediación}

Hemos visto recientemente que, la idea de "instrumento" ha sido considerada la facultad esencial que posee el Logos y que nos permite hablar de su rasgo distintivo. También, se advirtió que el "instrumento" es algo que media entre quien utiliza el instrumento y sobre aquello en que es usado, reflexión que llevó a descubrir un defecto dentro de los estudios filonianos.

Por ello, la propuesta que se desarrollará ahora es simple, retomar esta idea de "instrumento" como eje imprescindible para cualquier estudio sobre el "Logos en sí", pero interrogando esta vez lo que significa ser instrumento en el caso del Logos, es decir, su ser mediador.

Ahora, volvamos a la división tomista que ya hemos propuesto, que son las dos funciones o acciones (actiones) que posee el instrumento: a) una es la instrumental (operationem instrumentalem) acción según la que es actuada en virtud de un otro agente, y, b) la acción propia (actionem propriam) que sigue a su propia forma (secundum propriam formam). Para luego aplicar una especie de procedimiento de intercambio salva veritate y ver que conclusiones podemos extraer de este.

(Ver figura I $)^{25}$ En el comienzo de la figura tenemos al instrumento, el cual ejemplificaremos con el cuchillo. Este posee dos tipos de acciones u operaciones, la primera a la izquierda es la operación instrumental, aquella acción que se puede realizar "mediante el instrumento", acción

$\overline{25}$ Las figuras I y 2 son de nuestra creación. Solo buscan representar la dualidad a la hora de comprender un instrumento. 
en la que utilizo el instrumento para algo, como, por ejemplo, preparar una comida, una ensalada. Esta primera operación del instrumento, a su vez, necesita y media entre dos elementos para que se realice tal acción; por un lado, el agente externo (aquél que prepara la comida mediante el cuchillo), y, por otro lado, la materia prima (aquello sobre lo cual se ejerce la acción y del cual se obtiene un resultado). La segunda parte de la figura, aquella que se encuentra al lado derecho, nos presenta la acción propia del instrumento, su facultad distintiva, aquello que lo hace ser lo que es. En un cuchillo en este caso es su filo, pues un cuchillo que no tenga filo y no pueda cortar, tan solo poseería la apariencia del cuchillo y no su acción distintiva, el cortar. Por ello, esta acción propia del cuchillo permite aquello que aparece en el lado izquierdo de la figura, pues sin la acción propia de "cortar" del cuchillo, no se podría realizar la acción instrumental de "preparar una comida".

\section{Figura I}

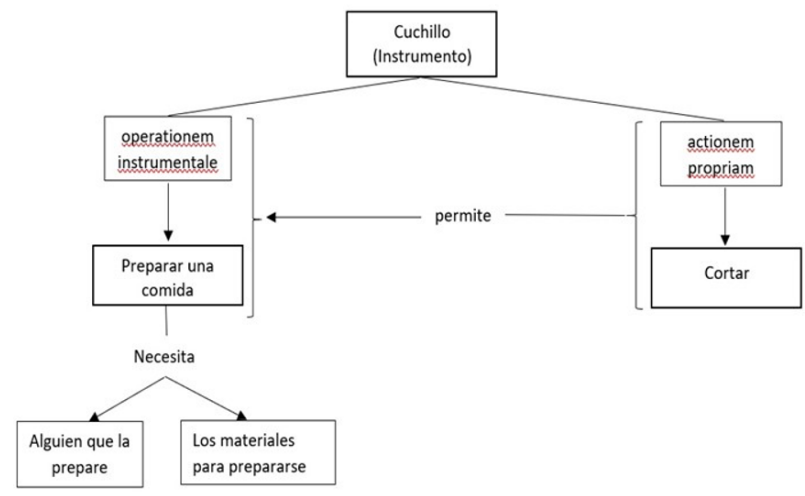

(Ver figura 2) Ahora veamos cómo queda la misma figura, pero con los intercambios que proponemos a propósito del Logos. En primer lugar y de manera obvia, aparece el Logos, instrumento del que hemos hablado. El Logos mediante su operación instrumental es quien permite establecer una mediación o vínculo entre el Creador y su creación, tal como hemos visto mediante los planos en los que se manifiesta el Logos y que enuncié al comienzo.

En el caso de la figura I, el cuchillo mediaba entre el cocinero y los ingredientes para ejecutar la acción instrumental de preparar la comida, siendo el cocinero el agente de la operación y la materia la parte 
pasiva. En el caso del Logos, aquello "necesario" para poder realizar la acción instrumental, no se establece tan solo una acción pasiva y otra activa, pues lo activo y lo pasivo pueden intercambiar roles en orden al tipo de mediación que se establece, pues puede ser tanto una mediación establecida por el Logos desde Dios hacia la humanidad, como también puede darse desde el hombre que quiere establecer una relación con Dios mediante la parte rectora de su ser, la recta razón que lo asemeja a lo divino.

\section{Figura 2}

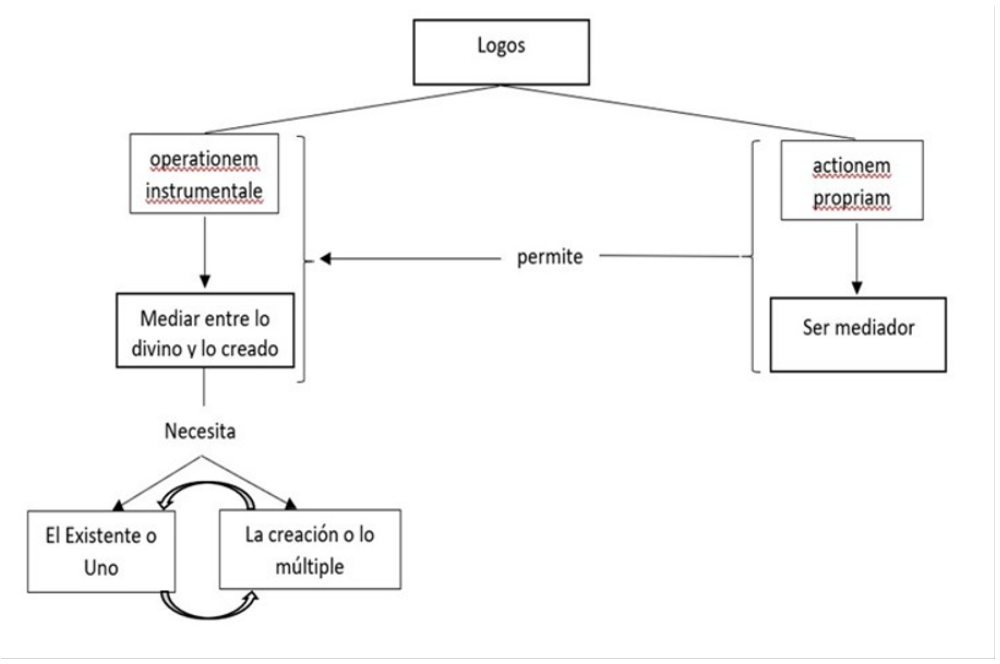

Parece de gran importancia esta representación de nuestra propuesta, pues ayuda a pensar el enfoque que han tenido las investigaciones (el lado izquierdo de la figura) sobre el rico concepto de "Logos".

Volvamos ahora a nuestra propuesta, pues parece importante en este momento investigar sobre aquello en que no se han detenido lo suficiente los estudios filonianos, lo que aparece en el lado derecho de la figura número dos, que es el "ser mediador" del Logos, antes que efectivamente ya se encuentre el Logos en una mediación específica. 


\section{El Logos en sí mismo mediador, su independencia ontológica y su necesidad}

En el tratamiento que se introducirá ahora, la propuesta será dar claves para la comprensión de la singularidad del Logos, tarea que será desarrollada en tres momentos: (I) la comprensión del Logos en sí mismo como mediador, aquella cualidad distintiva de esta entidad, (2) el análisis de la independencia ontológica del Logos respecto a su Creador, lo cual lo configura como una creatura real y no solo como una mera proyección, y, finalmente, (3) una respuesta al rol que juega esta entidad en el pensamiento filoniano, sobre su necesidad.

\section{I. El Logos en sí mismo mediador}

Se ha comentado anteriormente que, el propio Filón no trata sino escasamente la condición de "mediador" del Logos. Es solo en algunos de sus tratados mejor conservados como son los del comentario alegórico a la Biblia ${ }^{26}$, donde menciona o hace referencia a esta noción de mediador como, por ejemplo, cuando dice que el Logos se extiende desde el medio "ỏ $\pi$ ò $\tau \tilde{\omega} v \mu \varepsilon \dot{\varepsilon} \sigma \omega v$ " (Plant. 9) o cuando se nos dice que los lógoi $i^{27}$ son los mediadores $\left(\mu \varepsilon \sigma^{i} \tau \alpha \iota\right)^{28}$ de los que se debe servir el hombre debido a la inmensidad del Soberano, o bien intermediarios ( $\pi \alpha \rho \alpha \kappa \lambda$ ท́ por Dios al hombre por causa de su parentesco con el Logos ${ }^{29}$.

Esta falta de un pensamiento sistemático por parte del alejandrino no se configura como un mero olvido, pues efectivamente en su obra encontramos al menos una explicación de esta característica primordial, por ejemplo, nos dice Filón que el Logos es quien fue designado por el Padre que creó el universo, para "estar en medio" ( $\mu \varepsilon \theta$ ó $\rho\llcorner о \varsigma)$ para separar

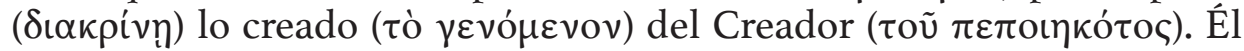

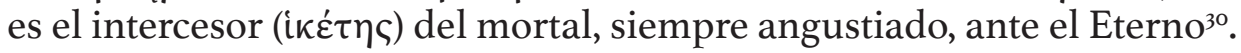

26 Con "comentario alegórico a la Biblia" hacemos referencia al género literario de interpretación alegórica que realizó Filón del Génesis. Han sido catalogados así veinte tratados del Corpus Philonicum. Ver en J. MARTíN. Filón de Alejandría, pp. 28-32. Estos tratados serán los que serán citados a lo largo de este capítulo.

27 Hay que recordar que los logoi o los angeloi son manifestaciones del Logos, pero en una intensidad menor que en el caso del Logos mismo. Sobre los ángeles como manifestaciones del Logos y por ello intermediarios, se puede ver el pasaje de Quaestiones et Solutiones in Exodum, II, I3, donde se nos dice que el Logos fue nombrado mediador " $\mu \varepsilon \sigma i \tau \eta \varsigma^{\prime}$, como aquel que está frente al Existente y es capaz de guiar al hombre por el camino de la virtud.

28 Somn. I, I42.

29 Praem. I63; 166.

30 Her. 205. 
En este pasaje se hace una clara alusión a la característica mediadora del Logos, por una parte, una referencia espaciotemporal, el "estar en medio" como el lugar propio del Logos, que separa dos realidades y marca una distinción ontológica entre ellas, y, por otra parte, se nos

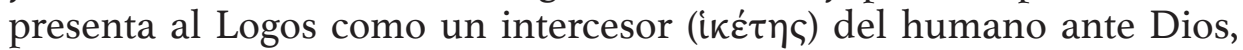
vinculándolos y salvándolos de la extrema separación.

Estas dos cualidades que se unifican en la concepción del Logos como mediador que se hace presente en el texto anterior (en el estar en medio), nos ayuda a comprender distintas funciones del Logos, como la de ser divisor ( $\tau о \mu \varepsilon ́ v \varsigma)$ y vínculo $(\delta \varepsilon \sigma \mu o ́ \varsigma)$, características contrarias que Filón atribuye al Logos, pero que se unen al entender algunas funciones instrumentales que debe desarrollar el mediador por excelencia, el Logos, que siendo quien está en medio (su actionem propriam), o, el mediador, cumple con diversas operaciones instrumentales (dividir y unir), con el fin de ser el garante de las funciones tanto del Creador, como de la creatura, como veremos más abajo.

El Logos como mediador nos permite entender al Logos de manera más sistemática, entendiendo la unidad en la multiplicidad de sus atributos o manifestaciones.

Este Logos, que según el texto anterior se compadece del hombre, también puede ser interpretado como el buen gobernante, al estilo de Moisés, quien intercede por el pueblo, pues es el hijo amado de Dios al cual el hombre debe elegir como su guía ${ }^{31}$, pues si Moisés es capaz de encarnar al Logos, a la razón de Dios y con ello al Dios manifestado, el hombre mediante este intermediario encarnado en un gobernante podrá ascender en su marcha hacia lo mejor. Esto mismo lo podemos corroborar en las palabras de Goodenough, quien nos dice: "Philo is quite ready to admit that the good ruler is the mediator of divine rulership to men, and although the ruler must be regarded as a human being in nature, his royal, official, voice is the voice not only of logos and divine law, but of God"32. Este gobernador, gracias a la mediación del Logos rector es quien podrá establecer un gobierno divino.

Así, el Logos se configura como mediador, pero veamos otro pasaje indispensable para hablar de la mediación del Logos.

En Quaestiones et Solutiones in Exodum, II, 68; ante la duda sobre el

3I Conf. 95.

32 E. GOODENOUGH. The Politics of Philo Judaeus. Yale University Press: New Haven, 1938, p. 58. 
significado de las palabras de Ex 25,22 "Te hablaré arriba del propiciatorio, entre los dos querubines", Filón responde que la Deidad está por encima de todo y que habla de manera correcta en medio de los poderes creador y soberano ${ }^{33}$, lo cual es concebido por la mente o interpretado por ella como la presencia del divino Logos que está apropiadamente

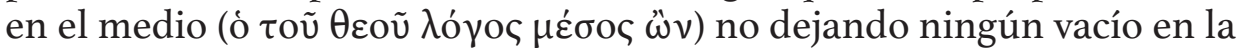

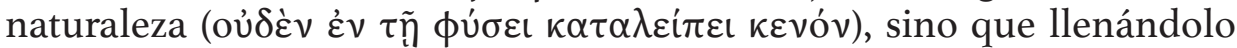
todo ( $\tau \dot{\alpha}$ ö $\lambda \alpha \pi \lambda \eta \rho \tilde{\omega} v)$ pues media ( $\mu \varepsilon \sigma \iota \tau \varepsilon \dot{\varepsilon} \varepsilon \mathrm{l})$ y es arbitro, generando

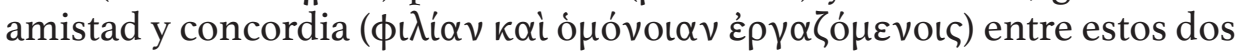
extremos ${ }^{34}$, Dios y el hombre.

Este pasaje es esencial para todo lo que hemos tratado, pues si el Logos adquiere tan múltiples facetas, no significa que sea un número infinito de cosas, sino que más bien adquiere esta multiplicidad de funciones para llegar al cosmos y a todo el ser humano mediante su acción instrumental, la cual está dada por su ser "mediador", o, acción propia que, en el texto se expresa como un "estar en medio", "llenándolo todo", como condición propia que le permite mediar, en el texto " $\mu \varepsilon \sigma \iota \tau \varepsilon u ́ \varepsilon ı "$, generando relaciones como la "amistad" y la "concordia" entre los seres, y, entre el hombre y Dios.

Este Logos, utilizando la imagen plotiniana del Intelecto es unimúltiple, pues por una parte, es uno en tanto primogénito ( $\pi \rho \circ$ ó́yovoৎ) de Dios y con ello el más viejo ( $\pi \rho \varepsilon \sigma \beta u ́ \tau \alpha \tau o v)$ de los seres, límite y vínculo entre Dios y la creación; pero por otra ya se encuentra en él la manifestación de la multiplicidad (en tanto mundo de las Ideas), que adquiere múltiples formas con el fin de entrar en contacto con la humanidad y ser el canal que traspase tanto la voluntad divina a los hombres como también el canal que logra remitir al Existente el progreso de la humanidad, siendo él mismo el "camino real" ${ }^{35}$ que ha de seguir la humanidad para el acceso a su divinización.

El Logos es quien está en medio de los extremos ( $\mu \varepsilon \dot{\sigma} \sigma o \varsigma \tau \tilde{\omega} v$

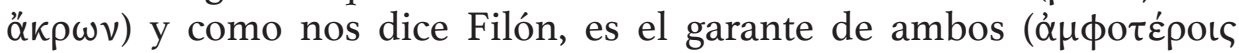

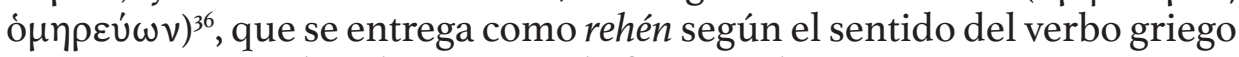

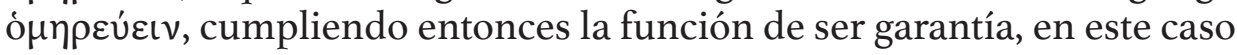

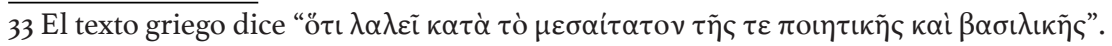

34 Sobre esta unión o reconciliación de los extremos Runia nos dice "The answer is that the divine Logos is stationed in the middle like a vowel in between consonants, acting as a mediator and persuasively reconciling the threats of the opposites." D. RUNIA. Philo of Alexandria and the Timaeus of Plato, p. I79.

35 Post. I02; Deus. I80.

36 En Her. 205. 
de ambos, Dios y la materia, lo cual en sentido metafísico coloca al Logos estrictamente como el fundamento no de la existencia del todo, sino de las funciones del todo, de la correcta naturaleza de las cosas, y, de la impenetrabilidad de la esencia divina.

Esto significa que este Logos es la causa de que el Padre se configure como padre, y, así, siendo su primer hijo, permite que la humanidad sea tal a través de su principio racional que lo penetra todo.

El Logos da sentido al caos primordial, mediante la actividad creadora que despliega en su enorme recorrido de la naturaleza ${ }^{37}$ y mediante su actividad rectora ${ }^{38}$ la gobierna, cuidando de manera providencial la creación ${ }^{39}$.

Esta esencia de mediación con la que hemos descrito al Logos y que se acaba de corroborar en los escritos del propio Filón, pueden también derivarse del propio vocabulario filoniano con el que se expresan ciertas características del $\operatorname{Logos}^{40}$, como la de ser el primogénito de Dios o imagen de Dios; el ser hijo primero del Existente lo configura como el más cercano a Él y siendo su imagen con la que se modelo la creación se presenta a la vez como el vínculo o mediador de toda creatura con Dios ${ }^{41}$.

37 Plant. 8-9.

38 Deus. I76; Leg. II, 6; Sacr. 44.

39 Agr. 5I.

40 Esta es la razón por la cual sin tener que explicar los pasajes en los que Filón habla del Logos como mediador, que ya vimos son pocos, los comentadores intuyeron esta característica primordial del Logos como mediador. Característica que, a pesar de ser supuesta por los eruditos, carecía del fundamento o explicación necesaria para su utilización.

4I Nuestra tesis acerca de la mediación como el rasgo esencial del Logos en todas sus facetas, nos permite sistematizar el núcleo del pensamiento filoniano acorde a las propias explicaciones que Filón da del Logos, que como hemos señalado, nos parece la más significativa aquella que se encuentra en Quaestiones et Solutiones in Exodum, II, 68; pues en ella se hace una doble referencia al Logos mediador, como el que está en medio y cumple la función de mediar entre Dios (por

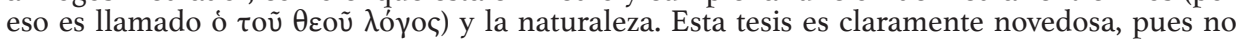
encuentra un correlato directo en la erudita tradición de comentadores filonianos, pero cabe mencionar que, recientemente Marija Todorovska ha señalado accidentalmente esta tesis, pero con consecuencias que a nuestro parecer no son del todo afortunadas, ni han sido del todo exploradas. Al menos en dos artículos, esta autora ha hecho una mención clara del Logos como un mediador o intermediario, pero ha acentuado que la característica fundamental del Logos no puede ser puntualizada en la mediación, pues no atendería a la multiplicidad de funciones que arrastra el Logos filoniano y que incluso no comprendería divisiones en el Logos, como el Logos trascendente e inmanente. Consideramos que la autora hace un correcto análisis del Logos mediador cuando lo presenta como la capacidad que logra reunir distintas manifestaciones de los poderes de Dios, y, que forma un nexo entre Dios y el mundo; pero, por el contrario, consideramos que se equivoca cuando dice que el Logos mediador no atiende las múltiples funciones del Logos, o, que es preferible mantener la pluri perspectiva nominal (multi nominal) acerca del Logos, pues incluso donde ella señala que el Logos mediador no abarca divisiones, como las de trascendente e inmanente, en el análisis detallado de estas manifestaciones del Logos, la función que se está cumpliendo es la de mediar, por un lado manteniendo al Existente en la Unidad, adquiriendo 
El Logos es el auténtico mediador de Dios y su creación. Permite que el Existente no quede totalmente aislado o desentendido de la multiplicidad como fue el motor inmóvil aristotélico, o, que quede demasiado comprometido e incrustado en la naturaleza como sería el $\delta \eta \mu$ เoupүós platónico.

\subsection{La independencia ontológica del Logos}

Ahora, quisiéramos abordar el problema de si este Logos mediador es o no una realidad independiente. Este problema no es necesariamente novedoso pues, la mayoría de los autores que han hablado sobre el Logos en Filón lo recogen, algunos de estos especialistas son, Daniélou, Runia, Niehoff, entre otros ${ }^{42}$.

A nuestro juicio este problema no es más que un dilema aparente, pues desde los propios textos filonianos es posible leer al Logos con una existencia distinta al Existente.

En el sistema de Filón el Logos siempre será un segundo Dios y cercano al cristianismo, como el primer hijo, la primera creación del Dios П $\alpha \tau \eta \dot{\rho} \rho$. Este Padre metafísico pudo amar a su primer hijo y con ello después a toda la creación, pero a contrapelo de la cosmovisión cristiana, este hijo no tiene la misma gloria que el Padre ${ }^{43}$, pues siempre

el Logos para sí la multiplicidad en la trascendencia del mundo inteligible, y, por otro lado, mediando como Logos inmanente en la naturaleza, imprimiendo en la creación las formas como copias del mundo inteligible, actuando el Logos inmanente como la fuerza activa de Dios. De esto último se puede ver la nota número I3 en, J. MARTENS. One God, One Law: Philo of Alexandria on the Mosaic and Greco-Roman Law. Brill Academic Publishers: Boston, 2003, p.73. La referencia a los dos artículos de la autora son los siguientes, M. TODOROVSKA. "The Concept of the Logos in Philo of Alexandria, Clement of Alexandria, and Origen" en Systasis. 29 (2016), pp.I-I5, p.9. Disponible en: https://repository.ukim.mk/bitstream/20.500.I2I88/1515/1/04.\%2007.\%20The\%2O Concepts\%200f\%20the\%20Logos\%20in\%20Philo\%200f\%20Alexandria\%20Clement\%20of\%20 Alexandria\%20and\%20Origen Systasis.pdf. Y, M. TODOROVSKA. "The Concepts of the Logos in Philo of Alexandria" en Ziva Antika / Antiquité Vivante. 65 (2015), pp.37-56, p.48; 53. Disponible en: https://repository.ukim.mk/bitstream/20.500.I2I88/1392/I/65.I-2.05.\%20Todorovska\%2C\%20 M.\%20-\%20The\%20Concepts\%200f\%20the\%2ologos\%20in\%20Philo\%20of\%20Alexandria. pdf.

42 Una de las formulaciones más significativas de este dilema es la que aparece en la tesis doctoral de Runia, en D. RUNIA. Philo of Alexandria and the Timaeus of Plato. Brill: Leiden, 1986, p. 207-208. Esta problemática Runia la plantea también en otros lugares, ver D. RUNIA. On the Creation of the Cosmos, p.I42.

43 La interpretación de un erudito del cuarto evangelio nos puede aclarar bien la jerarquía entre el Existente y el Logos, que en Filón es segundo Dios ( $\delta \varepsilon \dot{v} v \varepsilon \rho \circ{ }^{\prime} \theta \varepsilon$ có), menor al Padre. El Logos filónico a diferencia del Verbo cristiano debe ser visto en un sentido más filosófico que de fe, pues el Logos no es objeto de fe en el pensamiento del judeo-alejandrino mientras que el Existente sí. Dodd nos dice "Di conseguenza, gli elementi propri di una pietà, una fede e un amore personali che sono presenti in Filone senza trovare un accordo perfettt con la sua filosofia, nel Vangelo si trovano nell'atmosfera adatta. Il Logos di Filone non è oggetto di fede e di amore. Il Logos incarnato del quarto Vangelo, invece, ama ed è amato; amarlo e credere in lui costituisce 
estará subordinado al Existente. Ahora bien, esto no lo vuelve una mera manifestación de Dios, ni una cualidad suya, pues siempre será la primera alteridad que, como ya dijimos, es garante de la relación ${ }^{44}$ entre estas dos realidades tan alejadas.

El Logos aparece en una segunda fase del recorrido divino descrito en el Génesis ${ }^{45}$. Primero está Dios, luego su primer hijo el Logos, el primer otro, y finalmente, los hijos de Dios y del Logos. De este modo, está, por un lado, el Existente y por otro el sacratísimo Logos, también divino, pero segundo en el orden de la divinidad ${ }^{46}$.

El Logos también es presentado como maná o alimento celestial ${ }^{47}$ y esto porque Filón nos dice que

el maná es llamado "algo" ( $\tau i ́)$, que es el género de todas las cosas - y lo más genérico es Dios, lo segundo es el logos de Dios, y las otras cosas existen sólo por el logos, pues en los hechos las cosas son iguales a lo que no existen.

Del Logos se deriva todo lo demás que existe, pues de no ser por él, serían todas las cosas totalmente iguales a lo que no existe. Pero, ante todo, este logos es "algo", que en sentido estoico es el atributo común de todos los seres (SVF II, 333), incluso similar al ser (őv). Según esto, a propósito del problema de los universales, podríamos considerar a Filón como un realista platónico, para el cual Dios es el género generalísimo y el Logos el segundo género después de Él, siendo el género de todo lo demás, pero especie respecto del superior, cosa que lo subordina al

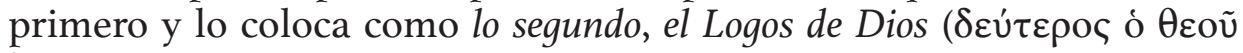

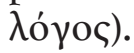

El Logos se diferencia del Existente al igual como un hijo se diferencia del padre. El Logos comparte de manera genética los atributos del padre y gracias a esto es que puede ser usado por Él como una

l'essenza di quella conoscenza di Dio in cui consiste la vita eterna. Ma con queste affermazioni abbiamo già anticipato il risultato delle analisi future." C. DODD. L'Interpretazione del Quarto Vangelo. Paideia Editrice: Brescia, I974, p. IO2.

44 Her. 205.

45 Conf. I46-I47.

46 Filón piensa la relación Existente-Logos como causa y efecto. Una relación de Padre e Hijo, en la que, de manera ético-espiritual, el hombre puede entrar en relación con Dios, en R. RADICE - G. REALE (ed.). Filone di Alessandria, p. IIO7.

47 "Uno extiende la vista hacia el éter y las revoluciones del cielo, y está educado para dirigir la vista hacia el maná, el Logos divino, el alimento celestial e imperecedero del alma que ama la contemplación. Los otros miran a las cebollas y a los ajos" (Her. 79). 
herramienta digna suya ${ }^{48}$.

En conclusión, la teología de Filón sí hace del Logos una hipóstasis, que se encuentra en todo, que conserva su unidad como intermediario y primer hijo (distinto) de Dios, lo cual nos lleva a concluir, al igual que hace Sterling hablando de la distinción entre Dios y su imagen, que Filón articuló un lenguaje sobre lo divino que lo llevó a la "hipostización"49.

\subsection{Acerca de la necesidad del Logos mediador}

Finalmente, no podemos terminar esta investigación sin abordar la necesidad del Logos mediador, pues este problema está unido a una pregunta básica de los textos filonianos, que es: ¿Qué está intentando salvar el Logos dentro del pensamiento metafísico filoniano?

Está claro que el Existente no puede entrar en contacto directo con la creación, pues existe una diferencia ontológica fundamental entre estas dimensiones, por un lado, está la simplicidad y unidad del Existente, y, por otro lado, está la complejidad o multiplicidad de la creación. Entonces, ¿Cómo Dios puede realizar la creación sin presentar en su esencia una alteración, o, una mera concepción de lo múltiple, impropio de la naturaleza divina?

Para Filón esto no es un problema, pues para él son las ideas -o el mundo inteligible- las que han engendrado todo ${ }^{50}$. Las ideas dan forma a lo que carece de ella ${ }^{51}$, como, por ejemplo, a la materia. De este modo, se resuelve el problema de la necesidad del Logos, pues se configura como la entidad que salva tanto la simplicidad y unidad de Dios, y entra en contacto con lo amorfo, para darle forma, voluntad traspasada mediante el Logos, pero que proviene del Existente y se instancia racionalmente mediante la acción del Logos y las ideas que permanecen en él.

El Logos mediador permite salvaguardar la trascendencia del Existente y reflejar en la creación -como un instrumento- su bondad.

48 Un bello análisis, sobre la relación entre el Existente y el Logos, realidades distintas, pero unidas casi cooriginariamente, nos la da Sandelin, que nos dice: "With more or less mythological language, Philo is able to describe the relationship between God, Wisdom, and the Word in terms of family, God being the father, Wisdom representing the mother, and the Word being the son" en K. SANDELIN. "Philo as a Jew" en Reading Philo. A Handbook to Philo of Alexandria. Wm. B. Eerdmans Publishing. Co.: Michigan, 2014, p. 35.

49 "Day one Platonizing Exegetical Traditions of Genesis I:I-5 in John and Jewish Authors" en The Studia Philonica Annual. I7 (2005), pp. II8-I40, p. I33.

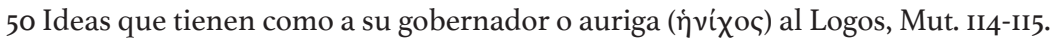

5I Spec. Leg. 328-329. 
Así, el Existente se configura como el Rey y el Logos como su lugarteniente, que realiza la voluntad del Rey, de forma racional y en contacto con el reino, "Dios, pastor y rey, los conduce según la justicia y la ley, poniendo al centro su logos, su hijo primogénito, el cual recibirá el cuidado de esta grey sagrada tal como el lugarteniente de un gran rey"52.

\section{Conclusión}

Finalmente, podemos concluir que el carácter distintivo del Logos es su mediación. Esto gracias al diagnóstico que se ha realizado sobre cómo Filón modula su comprensión del Logos mediador, a propósito de la posición media del mismo, que une y separa realidades ontológicamente diferentes, estableciéndose así, de manera explícita la acción propia del Logos, su mediación. Mediación que no consiste solo en estar en medio uniendo y distinguiendo estas dos realidades, sino que más bien, en ser garante de la relación entre ambas, cosa metafísicamente no menor.

El Logos debemos decir, es aquel garante o entidad que, se entrega como rehén para la consumación de la mediación. El Logos entregado como rehén permite una relación entre dos realidades opuestas, Dios y la materia, no como fundamento de tal o cual entidad, sino más bien permitiendo el vínculo entre ellas, siendo el garante de que cada entidad permanezca sin alteración, definiendo las cualidades de cada una de manera más completa e impidiendo su mezcla. El Logos es quien permite que, el Existente sea verdaderamente Creador y el universo permanezca como su creación.

Así, la metafísica filoniana va desde el Existente en Filón, pasando por la realidad intermedia, el Logos en sus múltiples facetas designadas por muchos nombres ( $\pi \mathrm{o} \lambda \cup \omega \dot{v} v u \mu \mathrm{ov} \dot{\tau} \pi \alpha \dot{\alpha} \rho \chi 0 v \tau \alpha)^{53}$, tales como mundo de las ideas y principios racionales de la realidad, para pasar por último al nacimiento del universo.

Podemos visualizar así dos aportes fundamentales de esta investigación, relacionados tanto a los aspectos más propios de la identidad intelectual de nuestro autor y su doctrina, como también, a las características propias del influjo del pensamiento filoniano en autores posteriores.

Respecto del primer punto, la doctrina del Logos entendido como

52 Agr. 5I.

53 Conf. 146. 
esencialmente mediador nos ayuda a poder definir con mayor exactitud la riqueza de la doctrina más importante de nuestro autor, y pone en evidencia el parámetro último a partir del cual pueden agruparse en un todo sistemático la gran variedad de sus manifestaciones, y, que sin este prisma parecen desconectados ${ }^{54}$.

Por otra parte, esta forma sistemática de entender al Logos, propia de Filón, nos puede ayudar a entender el pensamiento de otros autores estrechamente relacionados con la doctrina del alejandrino, Orígenes de Alejandría, que manifiesta en sus obras su gran aprecio por Filón ${ }^{55}$.

En efecto, Orígenes mismo acude a la autoridad del alejandrino, por ejemplo, cuando rebate la crítica de Celso a los escritos o escritores alegorizantes ${ }^{56}$. Con ello, la forma en que Orígenes habla de los escritos de Filón nos hace ver en cuan alta estima lo tenía, pues al articular partes de su propia teoría del Logos, el mismo Orígenes sigue a Filón, como por ejemplo cuando nos habla de la trascendencia de Dios con respecto a los $\theta \varepsilon o$ í, dioses cuyo modelo arquetípico es el Logos, idea que, como nos señala Daniélou, fue tomada por Orígenes de Filón ${ }^{57}$.

Así otro de los grandes campos de estudio que se abren a partir de esta investigación es el estudio de las relaciones existentes entre el pensamiento de los dos alejandrinos, pero que desde una concepción sistemática del Logos filoniano puede verse nutrida a partir de la lectura comparada de ésta con el Verbo-Jesús en Orígenes.

En resumen, podemos decir que el trabajo que se ha desarrollado en esta investigación tiene una doble direccionalidad en los avances de la filosofía tardo antigua y proto cristiana: Primero, en el caso del avance de los estudios filonianos puede contribuir a la búsqueda de una mayor definición o explicitación de aquello que debe entenderse como la esencia del Logos filoniano, concepto que si bien ha sido abundantemente

54 Específicamente pensamos que esta tesis refuta directamente la propuesta de Wolfson con respecto al Logos, propuesta que nos dice (según la reconstrucción de Daniélou) "its meaning is far from clear. Most authors see the Logos as an intermediate hypostasis between God and the

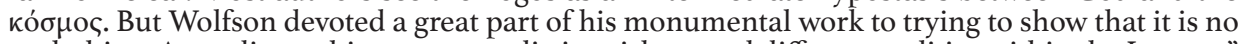
such thing. According to him one must distinguish several different realities within the Logos..." en J. DANIÉLOU. Philo of Alexandria. Cascade Books: Oregon, 20I4, p. 120.

55 "The main lines of usage are continued by Origen, who clearly knew the works of Philo in his library well and made extensive use of them... When, however, there is an apologetic context and Origen wishes to appeal to the authority of a Jewish author, he does cite Philo by name" en D. RUNIA. "Philo in the Patristic Tradition" en Reading Philo. A Handbook to Philo of Alexandria. Wm. B. Eerdmans Publishing. Co.: Michigan, 20I4, p. 272.

56 Específicamente los de Aristóbulo y Filón, en Contra Celso 4, 5 I.

57 J. DANIÉLOU. Orígenes. Sudamericana: Buenos Aires, 1958, p. 316. 
estudiado, permanece poco sistematizado desde el pensamiento mismo de nuestro autor, Filón. Y, en segundo lugar, con vistas al análisis de la filosofía y teología posteriores, aporta a comprender mejor el desarrollo crítico de la cristología patrística a propósito del Logos como hipóstasis, desarrollo que, a pesar de la negativa de algunos teólogos de aceptar su hilo conductor desde Filón, encuentra en el pensamiento filoniano su mayor antecedente no cristiano. 